EPOS, XVI (2000), págs. 15-27

\title{
LOS MITOS CLÁSICOS EN LA OBRA DE UN POETA ENTRE DOS MUNDOS: EL PADRE JUAN AROLAS
}

Juan Luis Arcaz Pozo

Universidad Complutense

\section{REsumen}

El presente trabajo analiza el uso que de los mitos clásicos hace el poeta Juan Arolas a lo largo de su producción, a caballo entre el movimiento neoclásico, ya agonizante, y los nuevos presupuestos románticos. Su postura permite vislumbrar el cambio de perspectiva que se da en esas dos corrientes literarias con respecto al mundo clásico y, en especial, a lo más representativo de éste: la mitología.

En el panorama literario español de la primera mitad del siglo XIX, cuando declinaba ya el movimiento neoclásico y despuntaba la nueva estética romántica, nos topamos con un poeta que se yergue con personalidad propia, contradictoria y marginal. Se trata del escolapio Juan Arolas ' (Barcelona 1805-Valencia 1849), un autor que conoció los estertores de la estética neoclásica y que abrazó

1 Sobre su vida y su obra, pueden consultarse los trabajos de J.R. LOMBA Y PEDRAJA, El Pa. dre Arolas. Su vida y sus versos. Estudio crítico, Madrid 1898 y L.F. Dfaz LARIos, La obra poética de Juan Arolas, Barcelona 1976, además de los datos aportados en las ediciones de estos autores mencionadas más abajo. 
tan pronto como pudo la bandera del incipiente movimiento romántico, a cuya difusión y cultivo dedicó buena parte de su obra literaria y de sus afanes, pues no hemos de olvidar que Valencia, ciudad en la que Arolas desempeñó la mayor parte de su actividad docente y literaria, fue uno de los focos peninsulares que con más ahínco importaron y difundieron el romanticismo ${ }^{2}$.

Por la especial vinculación de Arolas al mundo clásico - fue profesor de latín en las Escuelas Pías de Valencia-, ya desde su primera producción se empiezan a dejar sentir las enormes secuelas que en su poesía dejarán los grandes poetas latinos: Catulo, Horacio, Virgilio, Tibulo, Propercio y Ovidio señorearán en los versos de Arolas cobrando vida propia en una obra poética que con una actitud casi de centón se va a ver impregnada hasta la médula de los estilemas y motivos de la poesía latina, en especial de la de tipo amoroso, la elegíaca, que será la que marque en buena medida el carácter eminente y paradójicamente erótico de toda su producción literaria ${ }^{3}$.

USO ElEGÍACO DE LA Mitología EN SU OBRA DE JUVENTUD: LAS CARTAS AMATORIAS

En este sentido, su primera obra, titulada Cartas amatorias (de en torno al año 1830 , según la datación propuesta por L.F. Díaz Larios, su reciente editor ${ }^{4}$ ), revela a las claras esa vocación clasicista y en ellas las referencias al mito antiguo tienen el mismo cariz que en la poesía elegíaca latina; suelen servir de contrapunto o apoyatura a las digresiones pasionales del poeta que encuentra en tales referencias un lenguaje ampuloso y de hondas resonancias antiguas, aunque, al modo neoclásico, se reservan las más numerosas alusiones a los habituales dioses clásicos que pueblan el panteón del XVIII: Venus, Cupido, Baco, Apolo, etc. Y a veces se da la circunstancia de que, como Arolas parafrasea los originales latinos, encontramos las mismas alusiones mitológicas en sus versos que las que aparecen en los autores que le sirven de fuente e inspiración. Algunos pasajes, tomados al azar, pueden servir de ejemplo. Así ocurre en la primera de las cartas, donde haciéndose eco de la elegía I 1 de Tibulo escribe en dos ocasiones el escolapio:

${ }^{2}$ CF J.L. Alborg, Historia de la literatura española, vol. IV, Madrid 1982, p. 391.

- Sobre este particular, véase nuestro trabajo «Ecos clásicos en la poesía amatoria de Juan Arolas», Cuadernos de Filología Clásica (Estudios Latinos) 4 (1993) 267-299.

4 Cf. L.F. Diaz Larios, Obra completa de Juan Arolas, vol. I, Madrid, 1982, p. LXII. Entre otras ediciones de la obra del escolapio, merece la pena reseñar la de J.R. LOMBA Y PEDRAJA (Poesía del P. Arolas, Madrid 1928), por ser éste uno de los críticos, aparte de Draz Larios, que con más interés literario se ha aproximado a la producción del poeta barcelonés. 


\author{
Más feliz en la rústica cabaña, \\ Sin oír el clarín que Marte suena, \\ en la dorada edad vivió el amante, \\ exento de los males que hoy nos cercan \\ Otros del crudo Marte en rudas lides \\ sigan osadamente las banderas \\ y el sueño de sus noches interrumpa \\ el belicoso son de las trompetas...;
}

o bien hace esta variación sobre el conocido adulterio de Afrodita con el dios guerrero a propósito del tópico elegíaco de la militia amoris en parecidos términos a como lo refiere Ovidio en Am. I 9, 1-2 (Militat omnis amans et habet sua castra Cupido, / Attice, crede mihi, militat omnis amans):
Más dulce es la milicia del amante, distintas son sus armas y peleas, distinta la victoria: siempre vence el que dócil se rinde, humilla y ruega. ¿Quién contará las glorias de Cupido? En los brazos de Venus Citerea suspira aprisionado el crudo Marte olvidando su bárbara fiereza;

o esta otra alusión recogida en la respuesta a esta primera misiva del poeta en la que se introduce el rapto de Europa por Júpiter convertido el toro a propósito del poder absoluto que tiene el amor, capaz de subyugar incluso al soberano de todos los dioses:
¿Quién podrá separar dos corazones
heridos por la flecha penetrante del dios que, a su placer, turba la tierra, hace arder la campiña y ciudades?
El mismo Jove teme el poderío de ese niño sagaz, teme sus artes: no sea que otra vez, mudado en toro, con la carga gentil surque los mares;

o esta mención a diversos personajes del mito de la carta "A Inés» que le sirven al poeta de contrapunto para justificar la incitación a vivir el momento presente que se convierte el tema central de la epístola: 
Cuando yo, coronado de azucenas y de enojosa ropa desceñido, cantar debiera versos como Apolo por un coro de ninfas aplaudido; cuando elogiar a Baco y a Himeneo o a Jove, amador diestro en artificios, ya transformado en toro, ya cayendo del cielo, en lluvia de oro convertido...;

o, finalmente, esta habitual evocación de Arolas de la Edad de Oro que se incluye en la carta titulada «El amante de Célima a Flora» y que, como sucedía en la poesía latina - concretamente en Tibulo, el poeta al que sigue en este tema tan tratado por el escolapio-, se contrapone a la degradación del tiempo que le ha tocado vivir al poeta:

Feliz la juventud cuyas riquezas fueron un par de bueyes y un arado, la rubia mies, la pera sazonada y el añejo tonel del dulce Baco.

Su pompa era el adorno de las flores, la fragante violeta, el amaranto; su habitación, el bosque o la campiña; de pieles el vestido, lecho el prado. Amaron las zagalas al sencillo pastor que en su cantar fue aventajado; ni los furtivos besos se vendieron, ni de amor las delicias se compraron.

En definitiva, ejemplos todos de cómo Arolas introduce las alusiones mitológicas en una obra que sigue las pautas del género elegíaco y en la que se combinan y parafrasean los versos de todos los poetas latinos que de alguna forma tocaron el tema del amor.

\section{La mitología en MOLde bucólico: LAS ÉGlogas de ARolas}

Entre la fecha de composición de estas Cartas amatorias y el año de su muerte, publicó Arolas --además de, lógicamente, el resto de su producción poética, entre la que cabe destacar un poema dado a la luz en el Diario Mercantil de Valencia en 1839 basado íntegramente en el cuento de Cupido y Psique- un conjunto de cuatro églogas que, siguiendo en líneas generales los patrones bucólicos de Virgilio y Garcilaso, dejan entrever también el afán con que este poeta 
recreó los temas clásicos y mitológicos. En efecto, de estas cuatro composiciones pastoriles, dos de ellas desarrollan en extenso dos mitos ovidianos de las $\mathrm{Me}$ tamorfosis: la égloga II aborda el episodio de Polifemo y Galatea y la III el de Acteón, aunque también en la égloga $\mathrm{I}$, que es la que, por otro lado, más elementos formales y temáticos dependientes de Garcilaso evidencia, se incluyen algunas alusiones de tipo mitológico al modo con que el poeta renacentista incluía en sus versos las referencias míticas: como punto de partida o colofón de sus efusiones amorosas y subjetivas. Por otro lado, estas composiciones muestran asimismo una característica definitoria del estilo poético de Arolas y una constante que se da a lo largo y ancho de toda su obra: se trata de la capacidad metamórfica y mimética de su poesía que no tiene empacho alguno en adoptar los tintes líricos de los autores que le sirven de modelo y fuente, ya sean clásicos latinos o españoles s'. Así, Arolas es garcilasiano en la mencionada égloga I, gongorino en la II (pues su poema no es sino un homenaje poético al vate cordobés en tanto la historia de Polifemo está basada fundamentalmente en la conocida fábula de Góngora), virgiliano en la III (aunque sólo en aparencia o en lo que se refiere al armazón general de la bucólica, pues el contenido es enteramente de Ovidio, tanto en su faceta elegíaca como didáctica ${ }^{6}$ ) y, por último, también ovidiano en la IV, algo que, a juicio de Díaz Larios, manifiesta la pobreza lírica que Arolas desarrolla en estas composiciones por cuanto suponen que el lector «se encuentra ante una obra que es síntesis de otras» ${ }^{7}$. Con todo, vamos a pasar a analizar cuál es el uso que Arolas hace de la mitología clásica en estas composiciones que, en lo que a nosotros nos interesa, revelan el estado en que a estas alturas del romanticismo se encontraban ya las viejas leyendas antiguas.

La Égloga I es, como apunta Días Larios, una réplica casi exacta de la bucólica garcilasiana de Salicio y Nemoroso tanto en su métrica como en su contenido y en ella nos presenta el escolapio el diálogo amoroso que mantiene el pastor Silvio con su amada Erífile a veces interrumpido por la voz del poeta, que hace las veces de narrador omnipresente de los padecimientos eróticos del protagonista. En este sentido, y abundando en algo que ya hemos señalado antes, Arolas introduce los elementos mitológicos como mera apoyatura de las digresiones subjetivas de los personajes de su composición: no hay desarrollos extensos de ningún mito ni prolijidad expresiva en cuanto a su mención. Escuetamente se utilizan los nombres de los dioses más habituales del neoclasicismo

s Cf. L.F. DIAz LARIOS, ed. cit., p. LIX-LX.

- Sobre este égloga en concreto, remitimos a nuestro estudio «Presencia de Virgilio y Ovidio en la Égloga de Sileno de Juan Arolas», Cuadernos de Filología Clásica (Estudios Latinos) 10 (1996) 119-134.

7 Cf. L.F. Diaz LaRios, ed. cit., p. LX. 
que son traídos a colación con una cierta pereza funcional: están porque tienen que estar y su uso responde a unas necesidades impuestas por el tipo de composición en que se insertan. Así ocurre en la mención inicial y obligada a Cupido - además de una escueta referencia a Filomena, convertida aquí en plañidera de amores y no quejumbrosa por el luctuoso episodio de Tereo e Itis- que hace el poeta para encuadrar el argumento de su égloga:

Hay un rapaz $\tan$ lindo como ciego que avasalla los tiemos corazones y a dura alternativa los condena de bien y mal, placeres y aflicciones; siente el helado mar su activo fuego y en él bulle agitada la ballena; suspira Filomena de noche sus amores, oculta entre las flores o el parral frondoso en la enramada; no hay leve mariposa o flor pintada no sujeta a su ley y poderio, y así, con lengua osada, puede el rapaz decir: «el mundo es mío». Llámanle amor: su nombre, pronunciado al oído de tímida doncella, rosas hace brotar en su semblante, apareciendo así mucho más bella; víctimas mil ilustres ha contado de Venus Citerea el tierno infante. Como adalid triunfante $y$ armado con arpones, ya pisa los salones del magnífico alcázar, ya volando de la ciudad las selvas va buscando; se oculta en la cabaña que prefiere $y$, el tiro asegurando

a la humilde cabaña, al pastor hiere;

o esta otra que pone punto final a la intervención de Silvio en la que la referencia mitológica sirve de contrapunto a la meditación lírica y amorosa del personaje:

El ave del gran Jove ama la cumbre del peñasco monte inaccesible, y el cisne el agua pura y cristalina; 


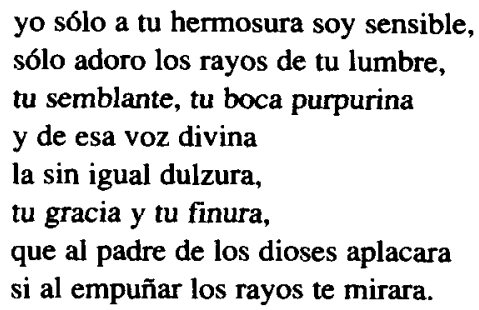

Y a la vez que estas referencias mitológicas salpican el modo expresivo de Garcilaso del que aquí hace gala Arolas, también, como es indefectible en toda su poesía, los ecos de poetas latinos vuelven a aparecer inundado todo el poema, tal ocurre en este parlamento de Erífile que denota palpables reminiscencias de la elegía III 9 del Corpus Tibullianum en que se habla de los celos que tiene Sulpicia por el excesivo amor a la caza que profesa su amado Cerinto, aunque, a pesar de ello, estaría dispuesta a seguirlo en su pasión con tal de estar a su lado:

¡Cuán grato me será al nacer la aurora del hombro suspender fechas agudas $\mathrm{y}$ al ciervo perseguir en su carrera por monte y prado y soledades mudas! ¡O bien parar la red engañadora en donde el tordo aprisionado muera, o a la grulla extranjera, con lazos engañada, llevarla a mi morada cuando el sol abrasara demasiado, y reposar entonces a tu lado!

¡Cómo te contaré yo las fatigas que hubiere tolerado persiguiendo a las fieras enemigas!

La Égloga II, dedicada exclusivamente a cantar los amores de Polifemo y Galatea, supone un vano intento de Arolas por emular la magna composición de Góngora, intento tal vez debido a que, como atinadamente señala Díaz Larios ${ }^{8}$, el escolapio había leído la fábula del poeta cordobés en las Poesías selectas castellanas que Quintana publico en 1829, lo que lo habría llevado, habida cuenta de su tendencia casi enfermiza a imitar a los poetas que leía, a redactar sin paliativos un poema sobre el mismo asunto. Desde luego, la presencia del texto gongorino

${ }^{8}$ Cf. L.F. Diaz L.ARIOS, ed. cit., p. LXI. 
es mucho más patente que la del texto ovidiano, que, recordemos, había desarrollado extensamente este episodio en el libro XIII de las Metamorfosis; así, además de múltiples reminiscencias textuales del Polifemo de Góngora, Arolas, en seguimiento de éste, suprime el detalle de los oseznos con que, según refiere Ovidio en su epopeya (Metamorfosis XIII 834-837), el cíclope pretende ganarse el favor de Galatea para que vaya a su cueva. Y todo ello aderezado con ecos verbales de otros muchos poetas señalados puntualmente por Díaz Larios en su estudio preliminar a las poesías del escolapio, entre los cuales destacan Lope de Vega y Fray Luis.

Un ejemplo más de cómo el ingrediente mitológico ya empieza incluso en Arolas a estar de más y a ser cada vez menos significativo, lo tenemos en la Égloga III en la que el poeta, siguiendo el esquema argumental de la Bucólica VI de Virgilio, nos presenta una historia relacionada con el mismo personaje que intervenía en la composición latina: Sileno. Sin embargo, cuando se nos pinta a Sileno entonando su canción, por similares motivos a los señalados por el vate de Mantua (esto es, a petición de unas jóvenes o de unas ninfas que, encontrándolo borracho, lo han atado y sólo tienen la intención de dejarlo libre a condición de que les cante una hermosa canción), el escolapio no incluye en dicha tonada las leyendas mitológicas que, en cambio, sí eran el contenido del parlamento de este personaje (recordemos que el Sileno virgiliano habla de los orígenes del mundo, de Pirra, Hilas, Pasífae y el toro, etc.). Arolas sustituye todas aquellas referencias al mito por un discurso centrado exclusivamente en una anécdota juvenil y amorosa de Sileno que, a pesar de ello, está construida sobre el argumento del mito de Escila narrado por Ovidio en sus Metamorfosis (XIII 898-968 y XIV 1-60) y aderezada por todos los motivos típicos y ya utilizados por el escolapio de la poesía elegíaca latina ${ }^{9}$.

Es, pues, esta égloga, compuesta ${ }^{10}$, como la de Acteón, en los últimos años de la vida de Arolas y cuando ya la locura que lo atenazaba lo había marcado definitivamente, un buen ejemplo del cambio de perspectiva del poeta ante el mundo clásico, al que ya no mira con los mismos ojos devotos y admirativos con que lo había contemplado en su obra de juventud, más plenamente anclada en la literatura y los temas clásicos.

Por su lado, la mencionada bucólica que toca el episodio de Acteón, la Égloga IV, también publicada en torno a 184461845 , supone una aproximación a la mitología clásica en muy parecidos términos a como se hace en la composición co-

9 Un análisis más minucioso de éstos puede verse en nuestro trabajo, ya citado, «Presencia de Virgilio y Ovidio...", pp. 126-134, especialmente en lo que se refiere a los elementos elegíacos y didácticos tomados de Ovidio y otros poetas para caracterizar a algunos de los personajes que intervienen en esta historia.

${ }^{10}$ Se publicó en el Diario Mercantil de Valencia el día 2 de abril de 1845 bajo el pseudónimo de las iniciales M.C. con que Arolas firmó algunas de sus composiciones utilizando las iniciales del nombre del editor valenciano Mariano de Cabrerizo. 
mentada antes. En ella de nuevo se nos enmarca el mito ovidiano en un ambiente por entero bucólico: la leyenda antigua constituye la canción que un pastor entona a su amada Eurídice y que culmina con una moraleja también relacionada con el amor (en el sentido de que los dioses, como es habitual que expresen los poetas elegíacos y a pesar de lo cuenta el mito, se apiadan con todo de los que aman). La égloga comienza con la consabida alusión del poeta-pastor al deleite que le supone verse alejado de cualquier afán (aquí incluso de cantar sucesos heroicos —y pues trompa de Marte generoso / no cuadra al labio mío»-) mientras disfruta de la paz y el sosiego del campo en compañía de su amor (proclama que en Arolas es deudora del espíritu pacifista avant la lettre de Tibulo —cf. elegías I 1 y I 10-):

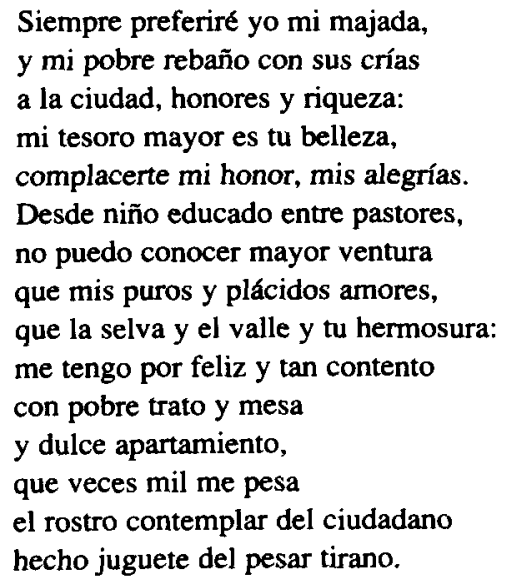

Tras este encuadre pastoril - $\tan$ acorde, por otro lado, con el ambiente que rodea al relato de Ovidio-, el pastor comienza a entonar su canción sobre el desdichado Acteón siguiendo bastante de cerca el relato ovidiano de Metamorfosis (III 138-252): en algunas ocasiones reproduce hasta textualmente el original latino, en otras amplifica - sobre todo los detalles y elementos bucólicoslas palabras del sulmonés y finalmente, en otras, reduce considerablemente la fábula antigua -en especial en lo relativo al momento en que Acteón es devorado por sus propios perros, sin duda el pasaje del mito más detallado por Ovidio-. Así, p.e., Arolas es fiel en la presentación de la historia reproduciendo casi literalmente los versos de Metamorfosis III 146-153:

cum iuuenis placido per deuia iustra uagantes

participes operum conpellat Hyantius ore:

«Lina madent, comites, ferrumque cruore ferarum, 
fortunamque dies habuit satis! Altera lucem

cum croceis inuecta rotis Aurora reducet, propositum repetemus opus. Nunc Phoebus utraque

distat idem terra finditque uaporibus arua:

sistite opus praesens nodosaque tollete lina!»",

cuando dice:

Acteón en extremo fatigado

de perseguir las fieras animosas

por alto monte, por tendido prado,

pedregales y selvas más frondosas,

llamó a todos sus dulces compañeros, que ocultos acechaban los oteros, y les dijo: dejar ñudosos linos, el hierro agudo y caracol torcido, que al extender sus rayos purpurinos

la aurora con fulgor apetecido, volveremos mañana a nuestro ojeo con mayor fuerza y singular deseo,

mientras que, por otro lado, abunda en la descripción del entorno de la gruta de Diana que Ovidio despacha en poco más de media docena de versos, de tal forma que lo que se dice en Metamorfosis IIl 155-162:

Vallis erat piceis et acuta densa cupressu, nomine Gargaphie, succinctae sacra Dianae, cuius in extremo est antrum nemorale recessu arte laboratum nulla; simulauerat artem ingenio natura suo; nam pumice uiuo el leuibus tofis natiuum duxerat arcum; fons sonat a dextra tenui perlucidus unda, margine gramineo patulos succinctus hiatus ${ }^{12}$,

" «...cuando / el joven hiantio congrega a sus compañeros de partida, que / vagan por apartadas espesuras, con amistosas palabras: "Las redes y las espadas, compañeros, están empapadas / con la sangre de las fieras; la jornada ha sido bastante afortunada. / Cuando la próxima Aurora, viajando sobre ruedas azafranadas, / nos devuelva la luz, reemprenderemos la tarea proyectada; / ahora Febo equidista de ambas metas y con su calor agrieta / los campos. Parad la caza por hoy y retirad las nudosas redes"» (según la traducción de A. RAMIREZ DE VERGER-F. NAVARRo ANTOLfN, OviDIO. Metamorfosis, Madrid 1995, p. 123).

12 «Había un valle poblado de pinos y picudos cipreses, / llamado Gargafia, consagrado a Diana con las haldas en cinto, / en cuyo más lejano confín hay una boscosa gruta, / fruto de ningún arte; la 
queda ampliamente desarrollado a lo largo de cinco estrofas, es decir, 30 versos, de los que podrían servir de ejemplo los siguientes:
Alrededor de una colina hermosa se ve el lugar más bello y encantado, por la naturaleza primorosa con extraño secreto fabricado para enseñar el arte, que es muy vano en copiar su belleza esfuerzo humano: porque de todas partes se levantan peñascos gigantescos y horrorosos, que al tímido mortal tal vez espantan, para ocultar los senos deliciosos de aquel recinto fresco y peregrino, vergel de Flora y su primor divino. Por entre las grietas revestidas de moho y de silvestres yerbecillas, precipitan sus fuertes avenidas torrentes claros, dulces fuentecillas que forman mil remansos deliciosos, do se bañan los cisnes melodiosos...

Y, en cambio, es tremendamente sucinto, según dijimos, en la descripción de la muerte de Acteón, a la que Ovidio dedica los versos 198-252 y Arolas sólo una estrofa:
Corriendo el infeliz por la llanura
fue visto de sus perros roedores
que, engañados al vivo en su figura, en su señor cebaron sus furores, hasta que, haciendo presa con herida, trágico fin pusieron a su vida.

Parece, en fin, como si el poeta se hubiera cansado ya del episodio y hubiera puesto un apresurado punto final que obvia tratar el fatal y espeluznante desenlace del mito. Tal vez la dulzura de Eurídice, la amada del pastor, que se echa a llorar una vez que el cantor llega a este punto, ha evitado a Arolas urgar

\footnotetext{
naturaleza con su propio ingenio / había imitado al arte; pues con piedra pómez viva / y conlegeras tobas había trazado un arco natural. / A la derecha murmura un pequeño manantial de agua cristalina, / con su anchuroso cauce rodeado de herbosas orillas» (cf. A. RAMIREZ DE VERGER-F. NAVARRO ANTOLíN, op. cit., p. 123).
} 
en tan sangrientos detalles que no cuadraban con el bello remanso de paz en que se desarrolla la escena pastoril. Por último, como colofón y consuelo ofrecido a Eurídice, el bucólico amante le indica a su doncella que no siempre los dioses se comportan como aquí lo hace Diana, pues en caso contrario serían muchos más los Acteones.

\section{LA MUERTE DEL MITO: REFERENCIAS MITOLÓGICAS DE AROLAS EN LA SILFIDA DEL ACUEDUCTO}

Si el mito se muestra y agonizante en estas últimas composiciones de Arolas ya plenamente imbuido de la nueva estética, es, sin embargo, en su poema titulado La Sílfida del Acueducto (1837), composición que marca el derrotero romántico que seguirá a partir de aquí el escolapio, donde mejor observamos el cambio de rumbo que el poeta imprimió a su obra y el abandono definitivo de los referentes clásicos en favor de la nueva y arrolladora estética romántica.

Este extenso poema, de algo más de 4.000 versos, en el que alternan con cierto confusionismo la novela histórica — cuyos elementos esenciales, adaptados al verso, tomó Arolas de la técnica cultivada por Walter Scott, haciendo coincidir el plano objetivo e histórico con el subjetivo e individual-, el poema romántico sentimental y el panfleto político ${ }^{13}$, el poeta nos presenta una historia de amor que se enfrenta radicalmente al orden eclesiástico establecido en una coyuntura político-social marcada por el profundo distanciamiento entre el Estado y la Iglesia que se agudizará con el decreto desamortizador de los bienes eclesiásticos. Arolas, como otros autores románticos que publicaron escritos sobre el asunto, se hará cuestión de este problema y se pondrá de lado del liberalismo más progresista arremetiendo virulentamente contra la Iglesia, si bien él nunca abandonó su vida religiosa a pesar de tan duras y acerbas críticas. En este sentido, es La Sílfida del Acueducto un documento de primer orden para el momento histórico que le tocó vivir a Arolas y un buen ejemplo de los intentos de un poeta nacido neoclásico que se apresura literariamente y magnis itineribus a subirse al tren del naciente romanticismo.

Su argumento, algo enrevesado y supuestamente basado en algunos datos históricos relacionados con la Cartuja de Porta-Coeli, en Valencia, con los que se mezclan elementos literarios tomados de autores bien conocidos por el escolapio - como es el caso de Lamartine- y otros tal vez autobiográficos o inventados por el poeta, nos presenta los amores desgraciados de dos jovenes que

${ }^{13}$ Cf. L.F. DIAZ LaRIos, ed. cit., p. LXVIII. 
ven cómo por las presiones familiares, religiosas y políticas tienen que renunciar a su relación. En este caldeado ambiente, que culmina con la muerte de los enamorados, el elemento mitologico no hace sino aparecer en un segundo plano evidenciándose el desgaste sufrido en su paso por el neoclasicismo y la falta de funcionalidad que demuestra en este tipo de obras atentas a otros intereses algunas veces distintos a los puramente literarios (e incluso, según hemos visto, en aquellas que tocan más directamente argumentos tomados de la mitología, como era el caso de la Égloga IV comentada antes). Díaz Larios señala con acierto cómo, descontextualizado ya, en esta obra el «Olimpo pagano alterna con el Cielo cristiano continuamente», cómo las alusiones «al mundo bucólico, a la diosa de los bosques... a Eos... a Venus y a Cupido» y a otros dioses más constituyen simplemente un uso de la mitología ramplón y vacío de contenido y estremecimiento, muy contrario al uso que se hace del mundo cristiano, que «funciona dentro el poema con el sentido religioso de quien cree en él, no como una literatización» ${ }^{14}$.

El poema de Arolas muestra una actitud ante lo clásico que nos posibilita tener una visión muy directa del cambio operado en la literatura romántica con respecto a la Antiguiedad: del fervor por todo lo relacionado con el pasado que lleva al poeta a vivir su vida a través de los códigos literarios antiguos se llega a la indiferencia hacia todo ello en beneficio de una literatura que tiene más presente la realidad mediata del escritor y que ve en los mitos antiguos un corsé demasiado estrecho para el cultivo de la libertad imaginativa y la creación poética. Arolas, pues, nos ofrece en su obra la muerte paulatina, obligada y en directo de los mitos clásicos en la poesía española de la primera mitad del siglo XIX. 